\title{
Philosophically speaking, how many species concepts are
}

\section{there?}

John S. Wilkins ${ }^{1}$

It's an old question in biology: what is a species? Many different answers have been given over the years, and there are indefinitely many "definitions" in the literature. Adding to R. L. Mayden's list of 22 definitions (Mayden, 1997), I counted 26 in play since the Modern Synthesis (2009a), and a new one, which I call the "polyphasic" concept (basically a consilience of many lines of morphological, ecological, genetic, and physiological evidence), has been implicitly extended from bacterial and other microbial contexts to macrobial species, although the terminology has not yet been transplanted (Colwell, 1970; Vandamme et al., 1996). However, on another count there are seven "basic" species concepts: agamospecies (asexuals), biospecies (reproductively isolated sexual species), ecospecies (ecological niche occupiers), evolutionary species (evolving lineages), genetic species (common gene pool), morphospecies (species defined by their form, or phenotypes), and taxonomic species (whatever a taxonomist calls a species).

Notice that some of these seven basic concepts are not concepts of what species are, that is, what makes them species, but instead are concepts based on how we identify species: by morphology, or the practices of taxonomists. Others are roughly equivalent. A gene pool is defined as a population of genomes that can be exchanged, and so a genetic species is basically a reproductive species. Evolutionary species are not what species are so much as what happens when some processes (such as ecological adaptation or reproductive isolation) makes them species that persist over long time. One common "concept" of species, the so-called phylogenetic species concept, is likewise a mix either of morphospecies, biospecies or evospecies or all of them (Wilkins, 2009b). The polyphasic concept is also based upon a method for identifying species through many kinds of evidence. Agamospecies are species that lack some property: sex. An

1 Philosophy, Bond University, Gold Coast, Queensland, Australia, and Philosophy, University of Sydney; email: john@wilkins.id.au. 
agamospecies is a not-biospecies species (although some, like G. G. Simpson and Ernst Mayr, simply denied they were species, which is a problem given that sex is a relatively rare property in the universal tree of life; it means most biological taxa do not come in species). So what makes an agamospecies a species? It can't be reproductive isolation, for obvious reasons, so it must be the only thing that we have left on the list: ecological niche adaptation (Wilkins, 2007). It could be chance, but if grouping happens by chance it is unlikely to be maintained by chance. In the absence of sex, therefore, we need ecological niche adaptation to keep the cluster from just randomly evaporating. Of course, few if any species are purely asexual in the sense that they don't ever exchange genes; microbes have several mechanisms to do this even if they lack genders or mating types and fail to reproduce by any other means than division. Some genetic material can be exchanged through viral insertion, through DNA reuptake in the medium after a cell has lysed, or by deliberate insertion of small rings of DNA, plasmids, through pili. "Horizontal" or "lateral" genetic transfer is probably as old as life itself. While this might introduce some genetic variation into a population, it is selection for a local fitness peak that makes the asexual genome not stray too far from the "wild type".

As sex becomes more frequent, rising from near zero recombination per generation up to the maximum of $50 \%$ exchanged for obligatorily sexual organisms, another factor comes into play. Increasingly, the compatibility of genomes, reproductive processes at the cellular, organ, and physiological level become important. In organisms with behavioral signaling (that is, with nervous systems and sensory organs), reproductive behaviours like calls and movements become important. Sex acts to ensure that the organisms that can interbreed tend to be those whose genome and anatomy are consistent enough. I call this "reproductive reach" $(2003,2007)$ : the more closely two organisms are related, the more likely they are within each other's reach as potential mates, and so the species is maintained by reproductive compatibility, and of course some ecological adaptation. This is very similar to a definition of "species" by the geneticist Alan Templeton (1989), who said that species were "the most inclusive population of individuals having the potential for phenotypic cohesion through 
intrinsic cohesion mechanisms", "that defines a species as the most inclusive group of organisms having the potential for genetic and/or demographic exchangeability." [My emphasis.] "Genetic" exchangeability here means the ability to act in the same manner in reproduction - any two members of the species are (more or less) interchangeable. "Demographic" exchangeability means that any two members of the species behave the same, ecologically, behaviorally and so forth, and are interchangeable (more or less). With these two causes of being a species, we can now narrow down the number of concepts to two: ecospecies or biospecies.

There's a philosophical matter to clear up. These causal explanations are just that: explanations. They are not the concept of species. There was a concept of species before we had any clear idea of what they might be. We identified species in the 15th century that are still regarded as species, and there wasn't the slightest hint of an explanation in the air at the time. And it's an old concept, too, although the first simply biological definition of "species" (a Latin word that means "form" or "appearance") waited until 1686 when John Ray defined it. Ray's definition was based on a simple observation: progeny resemble their parents. Species are those groups of organisms that resemble their parents. Versions of it go back to the Greeks. According to this, there is some power, a generative capacity, to make progeny resemble parents, and it seems to rely upon seeds. I call this the generative conception of species, and it was not only the default view before Darwin, but Darwin himself held it, as do nearly all modern biologists. It is what it is that the explanations explain. So technically there is only one species "concept", of which all the others, the 2 or 7 or 27, are "conceptions". The idea that there is one generic category into which there are put many "concepts" is a mistake made by Ernst Mayr (1963). In ordinary philosophical usage, it is the concept that is the category, and the definitions define, in various ways, that concept. Another mistake often made by biologists is to think that if there is a concept/category, there has to be a specified rank or "level" at which all species arise (see discussion in Baum, 2009). This seems to rely on the idea that because Linnaeus took Ray's concept of species and made it the lowest rank in his classification scheme, there has to be something that all and only species have as 
properties, and it has caused no end of confusion. That species all exist does not imply that all species have some essential property (any more than because we can usually identify what an organism is implies there is something that all and only organisms share). This philosophical error is called "essentialism", and it is a supreme irony that Mayr, the opponent of essentialism about individual species, was held in thrall to essentialism about taxonomic concepts.

Some people think that there are no species. Moreover, they wrongly think this view is a consequence of evolution and that Darwin himself denied there were any. Now what Darwin thought 150 years ago is of no real consequence to modern biology, but he didn't think species were unreal constructs; he thought there was no single set of properties species had to have. He was not a taxonomic essentialist. But neither is it the case that species are unreal because they shade into each other. In modern philosophy, there is an ongoing debate over whether one can have vague and fuzzy sets or kinds, but for science we need only a little logic and metaphysics: If we can identify mountains, rivers, and organisms, we can identify species, and they will tend to have a "family resemblance" (Wittgenstein, 1968). What is a species among primates will tend to be like species in all other close relatives. What is a species among lizards will (usually) be like what a species is in close relatives (some lizards are parthenogens; and have no males, where their nearest relatives are sexual, but in that case they are like their sexual cousins ecologically and morphologically; see Wilkins, 2003). But some think that species do not exist except in the minds of biologists and their public (Hey, 2001a, 2001b; Pleijel, 1999; Vrana \& Wheeler, 1992). So for them, zero. Our final score is: $26-27,7,2,1$ or 0.

My solution is this: There is one species concept. There are two explanations of why real species are species (see my microbial paper, 2007): ecological adaptation and reproductive reach. There are seven distinct definitions of "species", and 27 current variations and mixtures. And there are $n+1$ definitions of "species" in a room of $n$ biologists. 


\section{Bibliography}

Baum, D. A. (2009) Species as Ranked Taxa. Syst Biol, 58, 74-86.

Colwell, R. R. (1970) Polyphasic taxonomy of bacteria. Culture collections of microorganisms, 421-436.

Hey, J. (2001a) Genes, concepts and species: the evolutionary and cognitive causes of the species problem. New York: Oxford University Press.

Hey, J. (2001b) The mind of the species problem. Trends in Ecology \& Evolution, 16, 326-329.

Mayden, R. L. (1997) A hierarchy of species concepts: the denoument in the saga of the species problem. In: M. F. Claridge, H. A. Dawah \& M. R. Wilson (Eds), Species: The units of diversity. Chapman and Hall, London, pp. 381-423.

Mayr, E. (1963) Animal species and evolution. Cambridge MA: The Belknap Press of Harvard University Press.

Pleijel, F. (1999) Phylogenetic taxonomy, a farewell to species, and a revision of Heteropodarke (Hesionidae, Polychaeta, Annelida). Systematic Biology, 48, 755-789.

Templeton, A. R. (1989) The meaning of species and speciation: A genetic perspective. In: D. Otte \& J. Endler (Eds), Speciation and its consequences. Sinauer, Sunderland, MA, pp. 3-27.

Vandamme, P., Pot, B., Gillis, M., de Vos, P., Kersters, K. \& Swings, J. (1996) Polyphasic taxonomy, a consensus approach to bacterial systematics. Microbiol Rev., 60, 407-438.

Vrana, P. \& Wheeler, W. (1992) Individual organisms as terminal entities: Laying the species problem to rest. Cladistics, 8, 67-72.

Wilkins, J. S. (2003) How to be a chaste species pluralist-realist: The origins of species modes and the Synapomorphic Species Concept. Biology and Philosophy, 18, 621-638.

Wilkins, J. S. (2007) The Concept and Causes of Microbial Species. Studies in History and Philosophy of the Life Sciences, 28, 389-408.

Wilkins, J. S. (2009a) Defining species: a sourcebook from antiquity to today. New York: Peter Lang.

Wilkins, J. S. (2009b) Species: a history of the idea. Berkeley: University of California Press.

Wittgenstein, L. (1968) Philosophical investigations (G. E. M. Anscombe, Trans. Repr. of [3rd ed.] English text, with index. ed.). Oxford: Basil Blackwell. 